\title{
Alteration of plant hormones in transgenic rice (Oryza sativa L.) by overexpression of anti-apoptosis genes during salinity stress
}

\author{
Mohammad Ubaidillah · Fika Ayu Safitri - Sangkyu Lee $\cdot$ Gyu-Hwan Park $\cdot$ Kyung-Min Kim
}

Received: 26 August 2015 / Revised: 11 September 2015 / Accepted: 21 September 2015

(c) Korean Society for Plant Biotechnology

\begin{abstract}
We previously identified the rice gene, OsSAP, as an encoder of a highly conserved putative senescenceassociated protein that was shown to have anti-apoptotic activity. To confirm the role of OSSAP in inducing abiotic stress tolerance in rice, we introduced OSSAP and AtBI-1, a plant homologue of Bax inhibitor-1, under the control of the CaMV 35S promoter into the rice genome through Agrobacterium-mediated transformation. The OSSAP transformants showed a similar chlorophyll index after salinity treatments with $A t B I-1$. Furthermore, we compared the effects of salinity stress on leaves and roots by examining the hormone levels of abscisic acid (ABA), jasmonic acid (JA), gibberellic acid (GA3), and zeatin in transformants compared to the control. With the exception of phytohormones, stress-induced changes in hormone levels putatively related to stress tolerance have not been investigated previously. Hormonal level analysis confirmed the lower rate of stress in the transformants compared to the control. The levels of ABA and JA in $O S S A P$ and $A t B I-1$ transformants were similar, where stress rates increased after one week and decreased after a two week period of drought; there was a slightly higher accumulation compared to the control. However, a similar trend was not observed for the level of zeatin, as the decrease in the level of zeatin accumulation differed in both $O S S A P$ and $A t B I-1$
\end{abstract}

\footnotetext{
M. Ubaidillah · F. A. Safitri · K.-M. Kim ( $₫)$

Division of Plant Biosciences, School of Applied Biosciences,

College of Agriculture \& Life Science, Kyungpook National

University, Daegu 702-701, Korea

e-mail: kkm@knu.ac.kr

S. K. Lee

Research Institute of Pharmaceutical Sciences, College of

Pharmacy, Kyungpook National University, Daegu 702-701,

Korea

G.-H. Park

School of Ecology \& Environmental System, College of Ecology

\& Environmental Science, Kyungpook National University,

Sangju 741-711, Korea
}

transformants for all genotypes during the early period of salinity stress. The GA3 level was detected under normal conditions, but not under salinity stress.

Keywords Plant hormone, Rice response, Salinity stress, Anti-apoptosis genes, OSSAP, AtBI-1

\section{Introduction}

Salinity is a major factor causing reduction in crop productivity in agriculture and leading to deterioration of the environment. Improving the use of such marginal resources requires insight about their limiting effects on plant development. The release of salt-tolerant crops to optimize the use of salt-contaminated water and soil resources has been of high interest for the scientific community, but little success has been achieved to date, specifically, few major determinant genetic traits of salt tolerance have been identified (Flowers 2004; Munns 2005). Soil salinity is among the most damaging abiotic stressors affecting today's agriculture due to the unpredictable nature of rainfall (Zhang et al. 2006). Although maintenance of ionic and water homeostasis is necessary for plant survival, salinity decreases crop productivity by reducing leaf growth and inducing leaf senescence. This lowers the total photosynthetic capacity of the plant, thereby limiting its ability to generate further growth and harvestable biomass, and also to maintain defense mechanisms against stressors (Yeo 2007). Abiotic stress (e.g., salinity) act as messenger molecules that function at the early stage of signal regulation, stress adaptation, and programmed cell death (Kawai-Yamada et al. 2005a). Programmed cell death (PCD), or apoptosis, is a cellular suicide process that is important for development and adaptation to environmental stressors (Hückelhoven 2004). Among the important regulators of PCD, much interest has been centered on the BCL2-associated x-protein (Bax) as the pro-PCD factor (Kroemer 1997). Similarities in PCD exist in 
plants and animals, and the expression of the animal proapoptotic protein, Bax, in plants and yeast induces cell death (Sato et al. 1994; Hanada et al. 1995; Lacomme and Santa Cruz 1999; Kawai-Yamada et al. 2001). While homologous Bax proteins have not been identified in plants, genes in Arabidopsis thaliana that cause Bax-like lethality have been uncovered (Kawai-Yamada et al. 2005b). However, Bax inhibitor (BI-1) has been found in both animals and plants, and overexpression of BI-1 can inhibit the activity of Bax protein in plants and yeast (Sanchez 2000). BI-1 has been identified in Arabidopsis (Kawai-Yamada et al. 2004), tobacco (Lacomme et al. 1999), and barley (Eichmann et al. 2004). Interestingly, overexpression of pepper BI-1 in tobacco conveyed salt tolerance to several abiotic stressors (Isbat et al. 2009). The gene that acts to prevent apoptosis in plants might also play a role in adaptation mechanisms to various stress tolerances. Abiotic stress and PCD are considered detrimental factors in plants. Thus, research on these issues should include the study of plant mechanisms, by investigating the genetic and hormonal changes involved in complex biological pathways and processes. The major physiological processes believed to be involved in the control of plant growth under saline conditions are water relations, hormonal balance, and carbon supply, with their respective importance depending on the time scale of the response (Munns 2002). Plant hormones function as central integrators that link and reprogram the complex developmental and stress adaptive signaling cascades (Golldack et al. 2013). Simultaneous quantitative profiling of multiple classes of hormones provides a basis for defining additive, synergistic or antagonistic hormone activities and identifying hormone networks regulating plant functions (Aloni et al. 2006). Hormones interact by activating either a common second messenger or a phosphorylation cascade (Harrison 2012). While the core component of apoptotic machinery is a proteolytic cascade (Golldack et al. 2013), measurement of plant hormones is required to understand the regulation process of plant responses and their mechanism of anti-apoptosis regulators. The convergence points of hormone signal transduction cascades are considered cross-talk, and

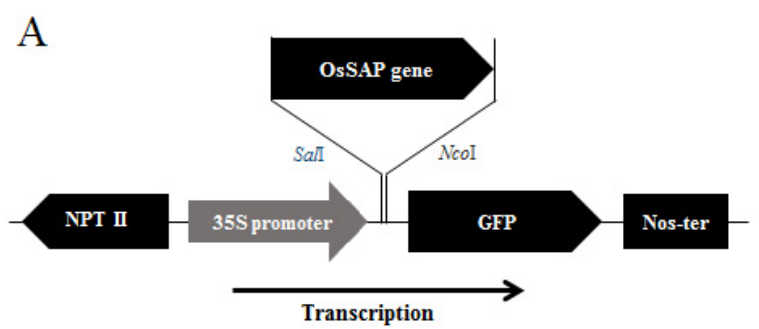

together they form a signaling network. In the present study, we examined the overexpression of OSSAP, which possesses anti-apoptosis activity, during the critical condition resulting from salinity stress. We investigated the correlation of antiapoptosis-like mechanisms with multiple stress tolerances by observing physiological changes. Furthermore, the overexpression of OSSAP was compared with a Bax inhibitor gene, AtBI-1. The experimental advantages in exploiting the rule pathways of anti-apoptosis genes with hormones change during salinity stress.

\section{Materials and Methods}

Plasmid constructs for $O S S A P$ and $A t B I-1$ transformation

The coding sequences of $O S S A P$ and $A t B I-1$ were cloned in the pBIN19 vector under the control of the CaMV 35S (P35S) promoter at a SalI-NcoI site. The reading frames were amplified by PCR using specific primers containing SalI and NcoI adapters (Fig. 1). The PCR products were digested with SalI and NcoI (TaKaRa, Japan) and the obtained fragments were ligated at the respective sites in pBIN19. Nucleotide sequence of the cloned coding region in pBIN19 was confirmed by sequencing. The generated pBIN19-OsSAP and pBIN19-AtBI-1 constructs were then transformed into the Agrobacterium tumefaciens strain LBA4404 and used for subsequent rice transformation.

\section{Agrobacterium-mediated transformation}

The overexpression constructs $\mathrm{pBIN19-OSSAP}$ and pBIN19AtBI-1 were introduced into a super virulent Agrobacterium strain (LBA4404). The pBIN19 construct contains $g f p$ as the reporter and kanamycin resistance gene (nptII) as the selectable marker. The Agrobacterium harboring either of the constructs was used for infecting the rice calli of Oryza sativa L. ssp. Japonica cv. Ilmi and Ilpum. The rice calli was produced by cultured rice seed in Murashige and Skoog (MS) callus

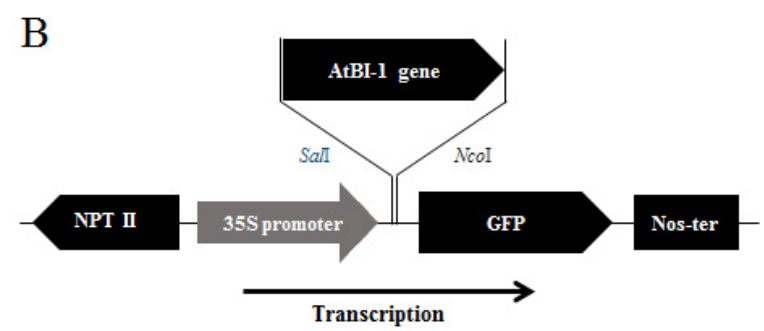

Fig. 1 Map constructs for OSSAP and AtBI-1 insertion into pBIN19 under the control of CaMV 35s promoter (P35s). A : Construct of pBIN19-OsSAP, B : Construct of pBIN19-AtBI-1 
induction medium (4.14 g/L MS vitamin powder, $2 \mathrm{mg} / \mathrm{L}$ 2,4-D, $0.3 \mathrm{~g} / \mathrm{L}$ casein hydrolysate, $30 \mathrm{~g} / \mathrm{L}$ sucrose, and $\mathrm{pH}$ 5.6) at $28^{\circ} \mathrm{C}$ under continuous dark conditions for 30 days. Agrobacterium was grown in a LB medium containing 20 $\mathrm{mg} / \mathrm{L}$ spectinomycin, $50 \mathrm{mg} / \mathrm{L}$ kanamycin, and $25 \mathrm{mg} / \mathrm{L}$ rifampicin. Optical density $\left(\mathrm{OD}_{600}\right)$ of the bacterial culture was measured and the final concentration was adjusted to an $\mathrm{OD}_{600}=1$. The culture was later centrifuged at $3,000 \mathrm{rpm}$ for $10 \mathrm{~min}$ and the resulting pellet was re-suspended in an equal volume of MS acetosyringone (MS-AS) medium (20 g/L sucrose, $10 \mathrm{~g} / \mathrm{L}$ glucose, $0.3 \mathrm{~g} / \mathrm{L}$ casein hydrolysate, $100 \mu \mathrm{M}$ acetosyringone, $\mathrm{pH}$ 5.6). The calli was immersed in the Agrobacterium suspension for $1 \mathrm{~h}$ at $28^{\circ} \mathrm{C}$ and kept for shaking at $180 \mathrm{rpm}$. The Agrobacterium suspension was drained off and the calli was placed on a sterile tissue paper. The infected calli was transferred to a MS co-cultivation medium (MS callus induction medium containing $50 \mathrm{mg} / \mathrm{L}$ 2,4-D and $100 \mu \mathrm{M}$ acetosyringone) and maintained under dark conditions at $28^{\circ} \mathrm{C}$ for 3 days. After co-cultivation, the infected calli was washed twice with sterile distilled water and once with an aqueous solution containing $250 \mathrm{mg} / \mathrm{L}$ carbenicillin, tapped on sterile tissue paper to get rid of adhering solution, and transferred to a MS elimination medium (MS callus induction medium containing $250 \mathrm{mg} / \mathrm{L}$ carbenecillin). The calli was cultured at $32.5^{\circ} \mathrm{C}$ under continuous dark conditions for 10 days. After the first sub-culture, actively growing pieces of calli were transferred to the MS selection and regeneration medium (MS basal medium supplemented with $1 \mathrm{mg} / \mathrm{L}$ 1-naphthaleneacetic acid, $3 \mathrm{mg} / \mathrm{L}$ 6-benzyl adenine, $3 \mathrm{~g} / \mathrm{L}$ casein hydrolysate, $30 \mathrm{~g} / \mathrm{L}$ maltose, $250 \mathrm{mg} / \mathrm{L}$ carbenecillin, and $40 \mathrm{mg} / \mathrm{L}$ geneticin) and kept at $28^{\circ} \mathrm{C}$ in a growth room under 16-h light and 8-h dark conditions. The growing of calli was sub-cultured every 15 days on the same medium The regenerated shoots were transferred to a rooting medium (half-strength MS medium without 2,4-D, supplemented with $50 \mathrm{mg} / \mathrm{L}$ geneticin). After four weeks, rooted plants were transferred to soil and hardened for four weeks. The hardened plants were transferred into plastic pots and were kept in a greenhouse until maturity. Leaf tissue from the regenerated plants and germinated seeds from the $T_{0}$ generation were tested for the presence of the transgene using PCR analysis.

\section{Extraction of DNA and RNA from rice tissues}

DNA from rice leaves was isolated using DNeasy Plant Mini Kit (QIAGEN, Germany) following the manufacturer's protocol. Leaf tissue $(100 \mathrm{mg})$ was ground in liquid nitrogen using mortar and pestle. The powdered tissue was suspended by vortexing in $450 \mu \mathrm{L}$ AP1 buffer containing RNase. The suspension was heated at $65^{\circ} \mathrm{C}$ for $10 \mathrm{~min}$, and $130 \mu \mathrm{L} \mathrm{AP} 2$ buffer was added followed by incubation at $4^{\circ} \mathrm{C}$ for $5 \mathrm{~min}$. The lysate was centrifuged at 13,000 rpm for $1 \mathrm{~min}$ using QIAshredder spin columns. The flow-through was transferred into a new tube and 1.5 volume of AP3/EtOH (30:60) was added. The mixture was transferred into a DNeasy spin column to allow the binding of DNA to the column. The columns were washed twice using Buffer AW (500 $\mu \mathrm{L})$ followed by $1 \mathrm{~min}$ of centrifuging to remove any residual liquid in the column. DNA was eluted in $50 \mu \mathrm{L}$ nuclease-free water into a $1.5-\mathrm{mL}$ tube.

Total RNA was isolated from leaf and root tissues using RNeasy Plant Mini Kit (QIAGEN, Germany) following the manufacturer's protocol. The sample $(\sim 100 \mathrm{mg})$ was powdered in liquid nitrogen using mortar and pestle, suspended in $\beta$ mercaptoethanol containing RLT buffer $(450 \mu \mathrm{L})$, and vortexed. The lysate was placed in a QIAshredder spin column and centrifuged at 13,000 rpm for $1 \mathrm{~min}$. The flow through was transferred to a new tube and 0.5 volume ethanol $(99 \%)$ was added. The mixture was transferred into an RNeasy spin column and centrifuged for $1 \mathrm{~min}$. The column was washed with buffer RW1 $(700 \mu \mathrm{L})$ and subsequently with buffer RPE $(500 \mu \mathrm{L})$. After an additional centrifugation for $1 \mathrm{~min}$ to remove any residual liquid in the column, RNA was eluted in RNase-free water $(30 \mu \mathrm{L})$.

Polymerase chain reaction (PCR) and Reverse transcriptase PCR (RT-PCR) analyses

The primers used for amplifying a 420-bp fragment of OsSAP gene were: 5'-CCTTTCCATTTGGGAATCCAGCC-3', and 5'-GCCCAGGGTTTCACCAGGAAGTT-3'. The PCR conditions used were: $94^{\circ} \mathrm{C}$ for $10 \mathrm{~min}$ followed by 45 cycles of $94^{\circ} \mathrm{C}$ for $30 \mathrm{~s}, 57^{\circ} \mathrm{C}$ for $30 \mathrm{~s}, 72^{\circ} \mathrm{C}$ for $1 \mathrm{~min}$, and a final extension at $72^{\circ} \mathrm{C}$ for $5 \mathrm{~min}$. For amplification of $\mathrm{AtBI}-1$ gene, the primers used were: $5^{\prime}$-ATGGATGCGTTCTCTTCCTT-3' and 5'CAGCCCCTCAGTTTCTCCTT- $3^{\prime}$, which generated a 720bp fragment. The PCR conditions used were: $94^{\circ} \mathrm{C}$ for $10 \mathrm{~min}$ followed by 45 cycles of $94^{\circ} \mathrm{C}$ for 30 seconds, $55.5^{\circ} \mathrm{C}$ for 30 seconds, $72^{\circ} \mathrm{C}$ for $1 \mathrm{~min}$, and a final extension at $72^{\circ} \mathrm{C}$ for 5 min. The PCR products were visualized after electrophoresis on $1 \%$ agarose gels.

The expression of the transgenes was analyzed by RT-PCR using SuperScript III One-step RT-PCR system with Platinum Taq DNA Polymerase (Invitrogen, USA). RT-PCR was performed using a $2 \times$ reaction mixture $(25 \mu \mathrm{L})$, a forward and reverse primer $(1 \mu \mathrm{L})$ and 20 pmole $/ \mu \mathrm{L}$, SuperScript III RT/Platinum TaqMix $(25 \mu \mathrm{L})$, and total RNA (500 ng). The gene specific primers for amplification of a 147-bp product 
from AtBI-1 were 5'-GTCTGCCTTTG GAGCTTACC-3' (forward) and 5'-GCACCTTC AAGAACAGCAGA-3' (reverse). The primers that produced a 420-bp product from OSSAP were 5'-CCTTTCCATTTGGGAATCC AGCC-3' (forward) and 5'-GCCCAGGGTTTCACCAGGAAGTT-3' (reverse). The cycling conditions for the RT-PCR were: $94^{\circ} \mathrm{C}$ for $2 \mathrm{~min}$, $94^{\circ} \mathrm{C}$ for 15 seconds, $60^{\circ} \mathrm{C}$ for 30 seconds, and $72^{\circ} \mathrm{C}$ for 1 $\mathrm{min}$. The amplification reaction was carried out for 40 cycles with a final extension at $72^{\circ} \mathrm{C}$ for $10 \mathrm{~min}$.

Real time PCR analysis

cDNA was synthesized from total RNA using a qPCRBIO cDNA synthesis kit (PCR Biosystem, USA) using the procedures described by the manufacturer. The reaction mixture contained total RNA $(1 \mu \mathrm{g}), 5 \times$ Synthesis Mix $(4 \mu \mathrm{L})$, $120 \times$ reverse transcriptase $(1 \mu \mathrm{L})$, and nuclease free water in a final volume of $20 \mu \mathrm{L}$. The first strand of cDNA was synthesized under the following incubation: $27^{\circ} \mathrm{C}$ for $10 \mathrm{~min}$, $42^{\circ} \mathrm{C}$ for $30 \mathrm{~min}$, and $85^{\circ} \mathrm{C}$ for $10 \mathrm{~min}$ to inactivate the reverse transcriptase. The real-time quantitative qRT-PCR analysis was carried out using real-time PCR Pre-mix qPCRBIO SyGreen Mix Lo-Rox (PCRBIOSYSTEMS, UK) according to the manufacturer's protocol. The thermal cycling and fluorescence detection was performed using an Eco Illumina Real-Time PCR machine and an Eco Real-Time PCR system software (Illumina, USA). A melting curve analysis $\left(60^{\circ} \mathrm{C}\right.$ at a heating rate of $0.1^{\circ} \mathrm{C}$ ) was performed to ensure that only the required $\mathrm{PCR}$ product at a specific melting temperature was measured. The real-time PCR reactions were performed in triplicate for each cDNA sample. Following amplification, the experiment was converted to a comparative quantification (calibrator) experiment type and analyzed using the Eco software (Illumina). The rice actin gene (Os1 1g0247300) was used as an endogenous control.

Flanking sequence tags (FSTs) analysis

Genomic DNA ( $\sim 100 \mathrm{ng})$ from each $\mathrm{T}_{1}$ line was digested with 4-5 units BfaI (New England Biolabs, $\mathrm{UK}$ ) in a $20-\mu \mathrm{L}$ reaction volume for $\sim 5 \mathrm{~h}$ at $37^{\circ} \mathrm{C}$, followed by inactivating the enzyme at $65^{\circ} \mathrm{C}$ for $10 \mathrm{~min}$. An aliquot $\left(5^{-10} \mu \mathrm{L}\right)$ of the restriction reaction was used for ligation of $B f a I$ adapters ADP1 (5' -CTAATACGACTCACTATAGGGCTCGAGCGGCCGG GCAGGT-3') and ADP2 (5'-TAACCTGCCCAA-3'). Both $B f a I$ adapters $(12.5 \mathrm{pmol})$ were applied to the digested fragments using T4 DNA ligase (3 U; New England Biolabs, UK) by incubating the ligation mixture $(20 \mu \mathrm{L})$ for $11 \mathrm{~h}$ at 14 ${ }^{\circ} \mathrm{C}$. Subsequently, the ligase was inactivated by incubation at
$65{ }^{\circ} \mathrm{C}$ for $10 \mathrm{~min}$. The first linear amplification was performed in a reaction $(50 \mu \mathrm{L})$ comprising the whole $B f a I$ digest, 200 nM of primers AP1 (5'-GGATCCTAATACGACTCACTA TAGGGC-3') and pBIN-TDNA1 (5'-CAATCAGCTGTTG CCCGTC T-3') for Right Border (RB), pBIN-TDNA3 (5'CCAAACGTAAAACGGCTTGT-3') for Left Border (LB), dNTPs (250 $\mu \mathrm{M}$ each), and Taq DNA polymerase (1.5 U; TaKaRa, Japan). Amplification was performed under the following parameters: $94^{\circ} \mathrm{C}$ for $2 \mathrm{~min}, 30$ cycles of $94^{\circ} \mathrm{C}$ for 35 seconds, $64^{\circ} \mathrm{C}$ for $1 \mathrm{~min}, 73^{\circ} \mathrm{C}$ for $1.5 \mathrm{~min}$, and a final extension at $73^{\circ} \mathrm{C}$ for $3 \mathrm{~min}$. An aliquot $(1 \mu \mathrm{L})$ from the first amplification reaction was used as a template for the second PCR; this reaction mixture $(50 \mu \mathrm{L})$ contained the AP2 (5'TATAGGGCTCGAGCGG C-3'), nested T-DNA primers pBIN-TDNA2 for the Right Border (5'-GTCTCACTGG TGAAAA GAAA-3'), pBIN-TDNA4 for the Left Border (5' -GGTCATAACGTGACTCCCTTA-3'), and adaptor primers. The other PCR constituents and cycling parameters were identical to the first amplification step. After determining the number and concentration of products formed in the second PCR, and fragments amplified from the region flanking the $\mathrm{RB}$ or LB of the T-DNA insert were sequenced. These sequences were analysed using them as the query in a BLASTN search against sequences of the binary vector, the genomic sequence assemblies, and all other existing sequences in an online database.

Salinity tolerance analysis

Viability assays were performed on $\mathrm{T}_{1}$ lines of $O S S A P$ and $A t B I-1$ transformants generated in this study. The salinity treatment was administered during vegetative stages of growth (until the 45-day-old stage). The sterilized seeds from nontransformed rice plants and $\mathrm{T}_{1}$ lines of OSSAP and AtBItransgenic rice were planted in plastic nursery trays and supplied with adequate water for growth. The growing plantlets were maintained in a greenhouse under natural light conditions (16-h light and 8-h-dark cycle) at an ambient temperature of $30 \pm 2^{\circ} \mathrm{C}$. For the salinity tolerance analysis, the different plant types were grown as described above. The salinity treatment was administered by irrigating the plants with $\mathrm{NaCl}$ solution $(200 \mathrm{mM})$ and maintaining the condition for 14 days. The chlorophyll index of the transformed plants was measured and compared with those of the control plants and served as an indication of salinity tolerance. The chlorophyll content was measured three times in different parts of the leaves by a chlorophyll meter (SPAD502; Minolta, Japan). The measurement was conducted in five replicates. 
Sample collection

Leaf and root samples were collected after 0,1 , and 2 weeks of salt treatment. The samples were used immediately after collection or were frozen in liquid nitrogen and stored at $-80^{\circ} \mathrm{C}$ for later use in gene expression and hormonal analysis.

\section{Quantitative analysis of major plant hormones}

Quantitative analysis of major plant hormones was performed as described by Pan et al. (2010). Fresh plant tissue (200 mg) was prepared in batches that included 24 calibration samples, as well as the control and unknown samples. The following is a list of all the necessary calibration, control and plant samples used: (1) 9 calibration samples to determine the correction factors, including replicates of each calibration sample at three concentrations $(10,100$, and $500 \mathrm{ng} / \mathrm{mL})$ of each plant hormone and the internal standard; (2) 15 calibration samples to determine the linearity, including triplicates of each calibration sample at five concentrations $(0,1,10,100$, and $500 \mathrm{ng} / \mathrm{mL}$ ) of hormones with a constant concentration of $50 \mathrm{ng} / \mathrm{mL}$ for the internal standard; (3) 3-5 replicates of each plant sample; and (4) one control sample with extraction buffer only. As recommended in the protocol, authentic plant hormones were used to optimize the HPLC-MS/MS setup before analyzing the biological samples, and plant tissues were spiked with known amounts of internal standards to test the recovery and quantitative accuracy. The leaf and root samples from plants exposed to salt stress were collected, immediately frozen in liquid nitrogen and stored in a freezer $\left(-80^{\circ} \mathrm{C}\right)$ until further analysis. The samples were ground in liquid nitrogen to fine powder with mortar and pestle. The tissue powder $(200 \mathrm{mg})$ from each sample was then transferred to $2-\mathrm{mL}$ screw-cap tubes, and $100 \mu \mathrm{L}$ working solution of internal standards (combining stock solution of the compounds designed as internal standards in Table 1 ; the final contents $1 \mu$ $\mathrm{g} / \mathrm{mL}$ ) were added to each tube. Thereafter, extraction solvent
$(700 \mu \mathrm{L})$ and a mixture of iso-propanol $/ \mathrm{H}_{2} \mathrm{O} /$ concentrated $\mathrm{HCl}(2: 1: 0.002, \mathrm{v} / \mathrm{v} / \mathrm{v})$ was added to each tube. If more than 50 $\mathrm{mg}$ of starting fresh tissues were used, the solvent volumes were adjusted, keeping the ratio of sample : solvent at $1: 10$ $(\mathrm{mg} / \mathrm{mL})$. The tube was put on a shaker at $100 \mathrm{rpm}$ for $30 \mathrm{~min}$ at $4^{\circ} \mathrm{C}$. One $\mathrm{mL}$ dichloromethane was then added to each sample, followed by further shaking for $30 \mathrm{~min}$ in a cold room $\left(4^{\circ} \mathrm{C}\right)$. The samples were subsequently centrifuged for $5 \mathrm{~min}$ at $13,000 \mathrm{rpm}$ at $4^{\circ} \mathrm{C}$. After centrifugation, two phases were formed with plant debris observed at the interface of the two layers. The lower phase $(900 \mu \mathrm{L})$ was transferred to a new screw-cap vial using a Pasteur pipette. The extracts were concentrated (but not completely dried) in a nitrogen evaporator with nitrogen flow. The concentrated extracts were re-dissolved again in $0.1 \mathrm{~mL}$ methanol. Extract $(50 \mu \mathrm{L})$ was analyzed by ESI-triple quadrupole mass spectrometer (HPLC-ESI-MS/MS, Applied Biosystems, USA) equipped with a reverse-phase $\mathrm{C}_{18}$ Gemini column $(150 \times 2.00 \mathrm{~mm}, 5-\mu \mathrm{m}$ particle size, Phenomenex, USA). The HPLC-ESI-MS/MS and multiple reaction monitoring MRM conditions and settings described in the equipment setup are presented in Table 1 . The binary system used solvent A ( $0.1 \%$ formic acid in water) and solvent B $(0.1 \%$ formic acid in acetonitrile) as a mobile phase. Separation was performed by altering the percentage time min/B (\%) gradient: 0/2, 2/20, 20/22, 22/25. Hormone levels were calculated from the ratio of the endogenous hormone peak, a known amount of internal standard spike, and from the actual fresh mass of the samples used for extraction.

\section{Result}

Overexpression of anti-apoptosis genes multi-tolerance in rice

The putative open reading frame of $O S S A P$ was predicted to code for 108 amino acids. Sequence analysis showed OsSAP

Table 1 Selected reaction monitoring conditions for protonated or deprotonated plant hormones

\begin{tabular}{cccccccccccc}
\hline PH & SM & Q1 & Q3 & Q2 $(V)$ & RT $^{\mathrm{a}}$ & IS & SM & Q1 & Q3 $^{Q^{2}(V)}$ & RT $^{\mathrm{a}}$ \\
\hline $\mathrm{ABA}$ & - & 262.8 & 152.6 & -16 & 7.96 & $\mathrm{~d}_{6}-\mathrm{ABA}$ & - & 269.1 & 158.8 & -16 & 7.98 \\
$\mathrm{GA}_{3}$ & - & 345.1 & 142.7 & -40 & 4.29 & $\mathrm{~d}_{2}-\mathrm{GA}_{3}$ & - & 347.1 & 142.7 & -40 & 4.31 \\
$\mathrm{JA}$ & - & 209.0 & 59.0 & -24 & 10.44 & $\mathrm{H}_{2}-\mathrm{JA}$ & - & 211 & 58.8 & -24 & 11.9 \\
Zeatin & - & 220.0 & 136.2 & 29 & 2.91 & $\mathrm{~d}_{5}$-Zeatin & - & 225.2 & 136.2 & 29 & 2.92 \\
\hline
\end{tabular}

ABA : 2-cis, 4-trans-abscisic acid, $\mathrm{d}_{6}$-ABA : 2-cis,4-trans-abscisic acid-[2H6]ABA, acid, $\mathrm{GA}_{3}$ : gibberellic acid, $\mathrm{d}_{2}$-GA : $_{3}$ [2H2] gibberellic acid, JA : jasmonic acid, $\mathrm{H}_{2}$-JA : dihydrojasmonic acid, d5-Zeatin : 6-[2H5] [(E)-4-hydroxy-3-methylbut-2-enylamino) purine], PH : plant hormones, SM : scan mode, Q1 : precursor ion selected in Q1, Q3 : product ion selected in Q3, Q2 : collision energy (V), RT : retention time, IS : internal standards. Retention times listed in this table were obtained from HPLC and column conditions mentioned in the protocol, HPLC : high-performance liquid chromatography 
encoded a senescence-associated protein that was also found in other species. A hydropathy plot indicated that the OsSAP protein had strong hydrophobicity throughout its length and possessed six possible trans-membrane regions (Ubaidillah et al. 2013). The senescence-associated protein was demonstrated to express under stress conditions. AtBI-1 is an anti-apoptosis gene found in Arabidopsis (Sanchez et al. 2000). OsSAP identified in rice was demonstrated to have anti-apoptotic activity similar to AtBI-1 after investigation in yeast. To examine the role of these two anti-apoptosis genes and their apoptosis inhibition mechanism in relation to multiple stress tolerances in rice we overexpressed these genes using distinct plasmid constructs for rice transformation. The constructs contained cloned $O s S A P$ and $A t B I-1$ under the control of a P35S promoter. More than $100 \mathrm{~T}_{0}$ putative transformants of the cultivars Ilmi and Ilpum were generated by an Agrobacterium-mediated transformation under nptII selection (Fig. 2). Two weeks after acclimatization, $T_{0}$ transformants were validated by PCR analysis, and confirmed five positive independent OsSAP transformants, two positive transformants in Ilmi, and three positive transformants in Ilpum. Twenty independent AtBI-1 transformants were also confirmed, twelve in Ilmi and nine in Ilpum. There were no phenotypic differences between $\mathrm{T}_{0}$ transformants and un-transformed plants in terms of appearance, growth, and flowering time. The T-DNA flanking regions from independent $\mathrm{T}_{0}$ lines of the OsSAP and AtBI-1 transformants harboring the transgenes as an intergenic single copy were selected for further analysis. The T-DNA flanking regions in independent transgenic rice overexpressing $O S S A P$ and $A t B I-1$ harbored the transgene as intergenic single copies. The positive $\mathrm{T}_{0}$ transformants were cultivated until maturity to harvest $\mathrm{T}_{1}$ seeds. The segregation in the $T_{1}$ generation was analyzed using PCR and the positive lines were later used for abiotic stress analysis in comparison to $C a M s r B 2$ transgenic rice.

Response of anti-apoptosis genes on salinity stress

As a negative regulator of Bax-mediated PCD, BI-1 has also been shown to be abiotic stress inducible. Heat shock and reactive oxygen species have been implicated as the abiotic stress factors inducing the expression of the AtBI-1 genes. OsSAP also negatively regulates programmed cell death and is a drought stress inducible gene. This gene has displayed improved tolerance to drought and salinity stress in yeast analysis. Effects of abiotic stresses on the expression of $O s S A P$ and $A t B I-1$ were extensively analyzed. The effects of drought and high salinity stress in the plants were evaluated separately for leaves and roots. To investigate the in vivo function of $O S S A P$ and $A t B I-1$, transformants were generated that over-expressed the $A t B I-1$ and $O s S A P$ genes. The positive $\mathrm{T}_{0}$ transformant lines were grown until maturity to harvest $\mathrm{T}_{1}$ seeds. $T_{1}$ seeds were planted under greenhouse conditions and the independent $\mathrm{T}_{1}$ transformants over-expressed the AtBI-1. OSSAP was similarly validated by PCR to confirm the presence of the transgenes. In the initial experiment, we tested whether the overexpressing lines of OsSAP and AtBI-1 were resistant to environment stress. The degree of symptoms for stress in the transformants differed from that in the nontransformed control plants. The transformant lines showed good performance under abiotic stress. The salt stress analysis used to investigate the response of transformants strongly
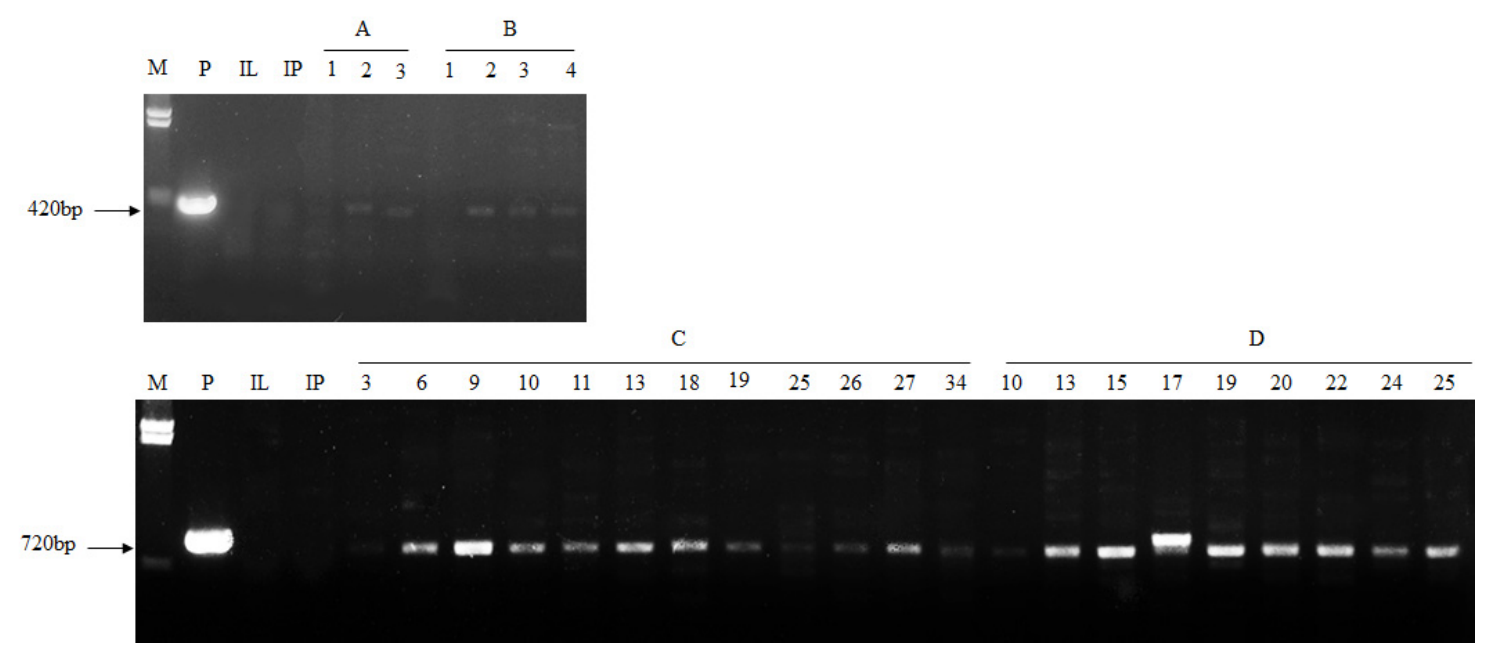

Fig. 2 Validation of $\mathrm{T}_{0}$ transformants through genomic PCR analysis. Amplicons were separated on a $1 \%$ agarose gel. M: $\lambda H$ Hind III marker (Fermentas, USA), P : plasmid, IL : Ilmi, IP : Ilpum, A : Numeric number of Ilmi transformed with OsSAP, B : Numeric number of Ilpum transformed with OSSAP. C : Numeric number of Ilmi transformed with AtBI-1, D : Numeric number of Ilpum transformed with AtBI-1 
suggested tolerance to abiotic stress. This result was further confirmed by the chlorophyll index after the salt treatment was applied to the non-transformed plants for two weeks (Fig. 3A). The different responses of transformants and nontransformants were obvious whereas all of the transformants survived and the non-transformed plants perished. The salt tolerance test was then performed using whole plants grown in the soil. Chlorophyll content data measured after one and two weeks were mean values obtained from 30 transformants. The OsSAP and AtBI-1 transformant chlorophyll content was higher under salinity stress compared to the controls, Ilmi and Ilpum. OsSAP and $A t B I-1$ transformants showed a good response under abiotic stress conditions. During salinity stress, both control Ilmi and Ilpum showed that chlorophyll slightly decreased by approximately 10 units after the one and two week treatment (Fig. 3B). Comparisons between transformants overexpressing anti-apoptosis genes and rice transformants demonstrated a similar response, suggesting that there is a similarity in stress tolerance operative mechanisms in these plants.

Gene expression analysis using RT-PCR and qPCR

To understand the gene expression pattern of selected genes and to correlate these to functional roles during stress, we performed gene expression analysis in rice leaves using
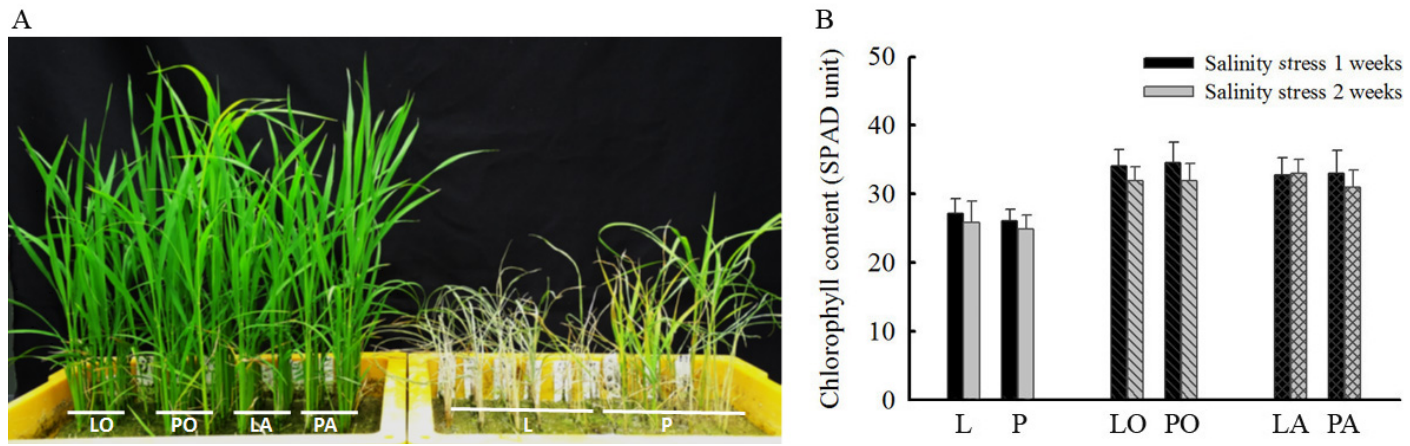

Fig. 3 The OsSAP and AtBI-1 transformant tolerance of salinity stress compared with control. A: Phenotype after salinity stress in transformant rice overexpressing compared with control, B: chlorophyll content after salinity stress in transformant rice compared with control. Mean \pm Standard deviation are given. L : Ilmi, $\mathrm{P}:$ Ilpum, LO : OSSAP $\mathrm{T}_{1}$ transformants in Ilmi, PO : OsSAP $\mathrm{T}_{1}$ transformants in Ilpum, LA : AtBI-1 $\mathrm{T}_{1}$ transformants in Ilmi, PA : AtBI-1 $\mathrm{T}_{1}$ transformants in Ilpum

A

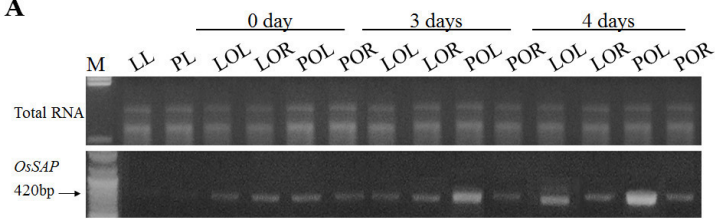

B

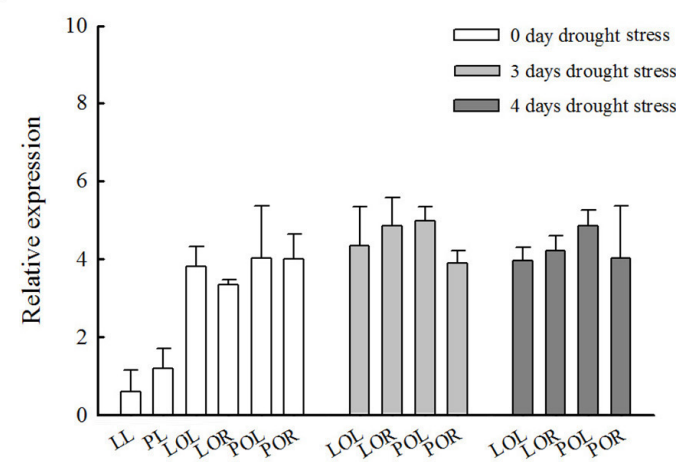

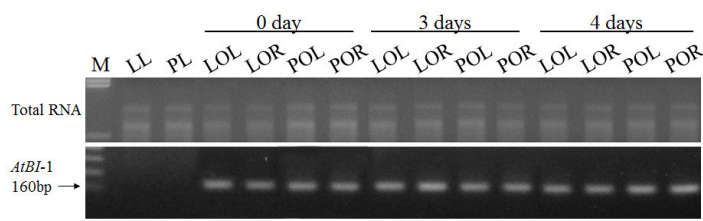

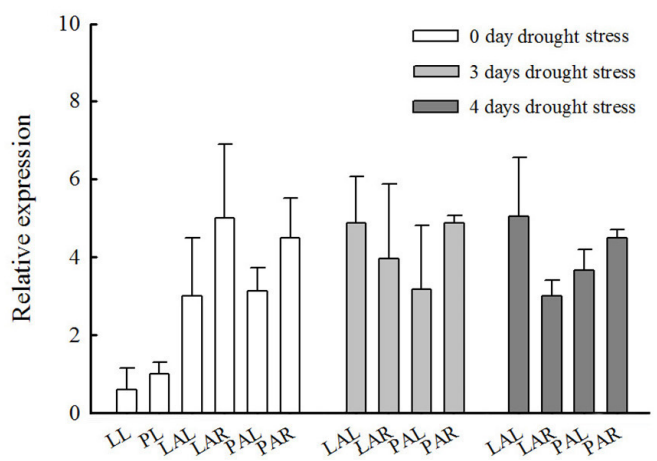

Fig. 4 Gene expression analysis under salinity stress condition. A : RT-PCR analysis of OsSAP (left) and AtBI-1 (right) transformants, B : Relative expression of OSSAP (left) and AtBI-1 (right) transformants after one and two weeks of salinity stress, respectively. Mean \pm Standard deviation are given. LL : control Ilmi-leaf, PL: control Ilpum-leaf, LOL : OsSAP Ilmi transformants-leaf, LOR : OsSAP Ilmi transformants-root, POL : OsSAP Ilpum transformants-leaf, POR : OsSAP Ilpum transformants-root, LAL : AtBI-1 Ilmi transformants-leaf, LAR : AtBI-1 Ilmi transformants-root, PAL : AtBI-1 Ilpum transformants-leaf, PAR: AtBI-1 Ilpum transformants-root 
RT-PCR and real-time PCR. The changes in transcript abundance for the genes that had been normalized and the expression in leaf and root tissue under salinity stress were essayed. Under salinity stress, the transcript OSSAP and $A t B I-1$ was detected from the earliest time point and was observed to be strongly induced after prolonged stress for one week in both leaves and roots of all the Ilmi and Ilpum transformants. The transcript level was maintained for two weeks of salinity stress (Fig. 4A). However, under salinity stress, the relative expression of OSSAP was higher and prolonged stress did not significantly affect the level of expression. The level of AtBI-1 under drought and salinity stress showed high expression, although the levels of expression varied (Fig. 4B).

\section{Alteration of hormone levels under salinity stress}

The effect of salinity stress on $\mathrm{ABA}, \mathrm{JA}$, and $\mathrm{GA}_{3}$ content was observed in transformants overexpressing OsSAP and AtBI-1 in transgenic rice leaf and root tissues while in critical condition at 0,1 , and 2 weeks of salinity stress. The ABA level did not increase in the Ilmi and Ilpum controls during the treatment, and decreased following two weeks of treatment. There was a slight increase in the level of ABA in the leaf tissue after one and two weeks of salinity stress for the Ilmi and Ilpum transformants overexpressing OSSAP, while no change was observed in the level of ABA in the root tissue. The ABA level in the leaf tissue of the Ilmi and Ilpum transformant overexpressing $A t B I-1$ also increased after one week, while there was no significant increase in the level of ABA in the root tissue that was prolonged with salinity stress for two weeks (Fig. 5). The level of JA in the control and OsSAP and AtBI-1 transformant rice decreased after one week of the treatment, and notable differences were not observed between the control and transformants. Salt treatment did not induce significant JA accumulation in shoots and roots of any genotype, but levels of JA slightly increased in both OsSAP and $A t B I-1$ rice transformants following two weeks of salinity stress compared to the control plant. This indicates that salinity stress may affect the JA level based on the extent of

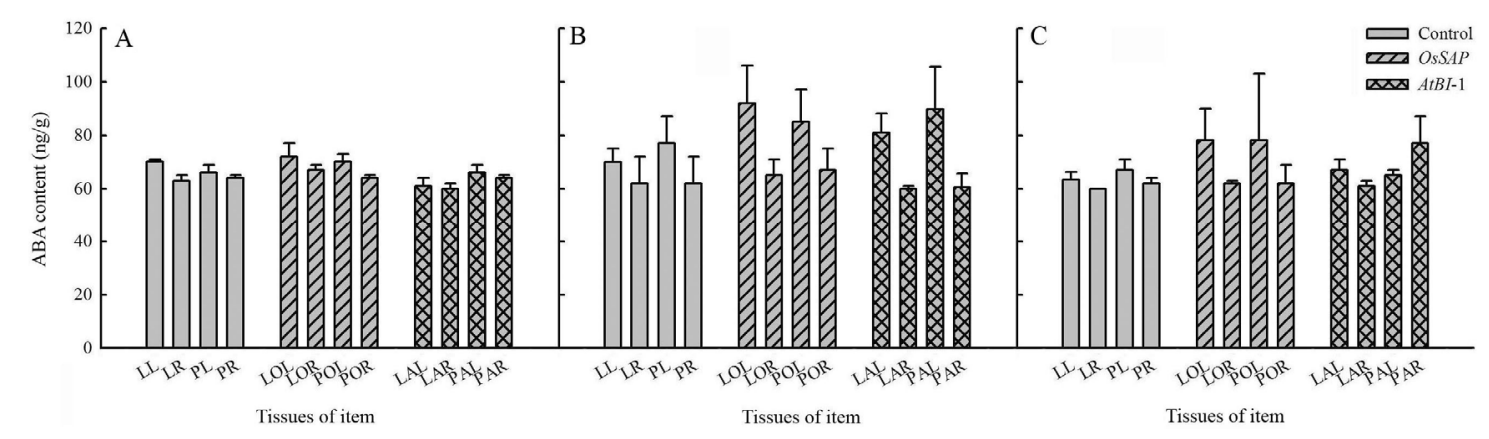

Fig. 5 Abscisic acid level of transformants compared with control under different salinity stress conditions. Mean \pm Standard deviation are given. LL : control Ilmi-leaf, LR : control Ilmi-root, PL : control Ilpum-leaf, PR : control Ilpum-root, LOL : OsSAP Ilmi transformants-leaf, LOR : OsSAP Ilmi transformants-root, POL : OsSAP Ilpum transformants-leaf, POR : OsSAP Ilpum transformantsroot, LAL : AtBI-1 Ilmi transformants-leaf, LAR : AtBI-1 Ilmi transformants-root, PAL : AtBI-1 Ilpum transformants-leaf, PAR : AtBI-1 Ilpum transformants-root

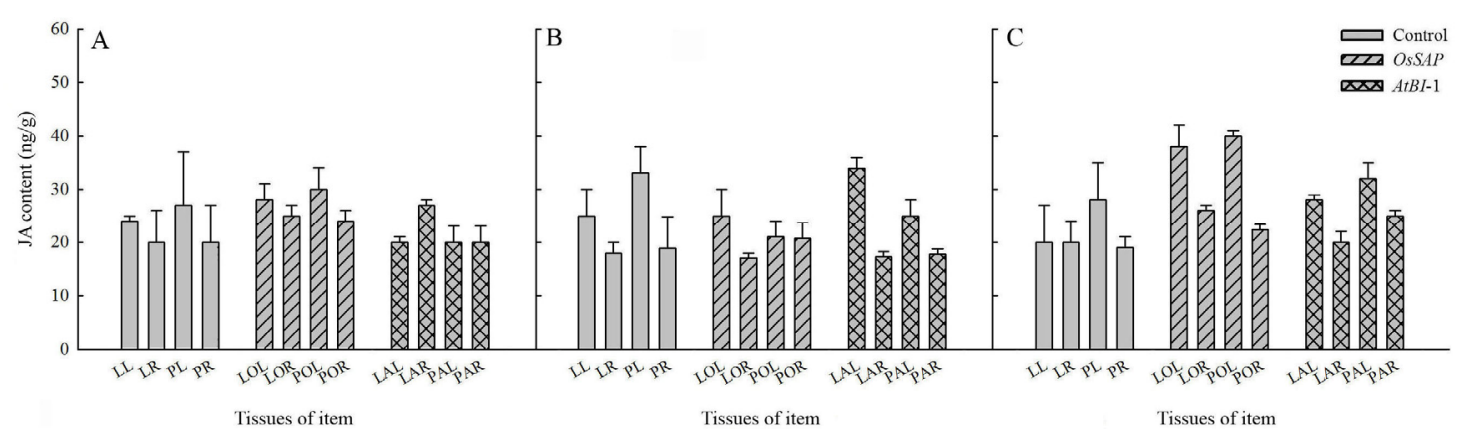

Fig. 6 Jasmonic acid level of transformants compared with control under different salinity stress conditions. Mean \pm Standard deviation are given. LL : control Ilmi-leaf, LR : control Ilmi-root, PL : control Ilpum-leaf, PR : control Ilpum-root, LOL : OsSAP Ilmi transformants-leaf, LOR : OSSAP Ilmi transformants-root, POL : OsSAP Ilpum transformants-leaf, POR : OsSAP Ilpum transformants-root, LAL : AtBI-1 Ilmi transformants-leaf, LAR : AtBI-1 Ilmi transformants-root, PAL : AtBI-1 Ilpum transformants-leaf, PAR : AtBI-1 Ilpum transformants-root 


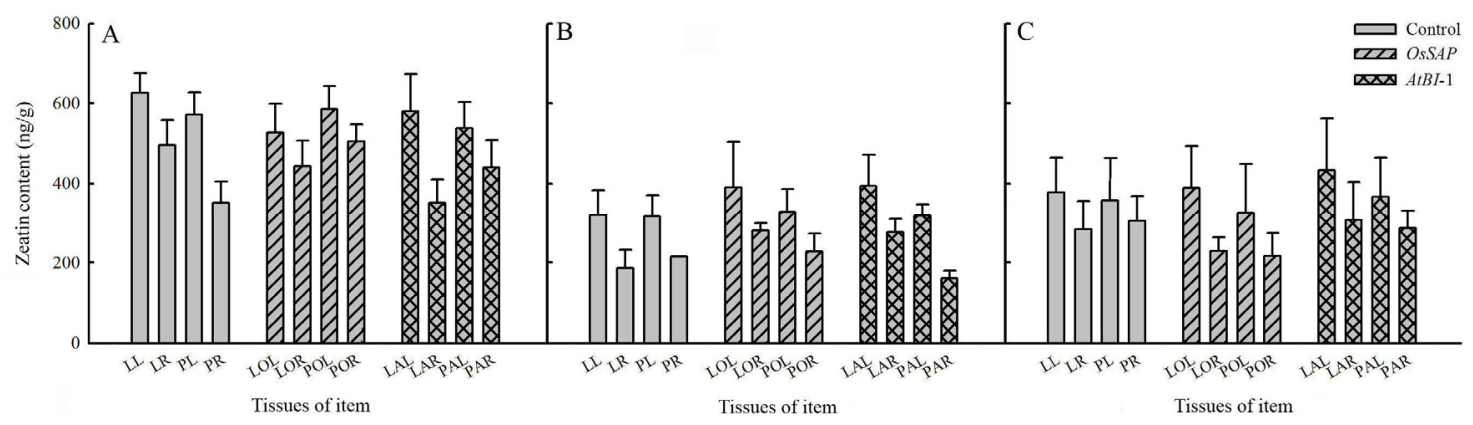

Fig. 7 Zeatin level in transformants compared with control under different salinity stress conditions. Mean \pm Standard deviation are given. LL : control Ilmi-leaf, LR : control Ilmi-root, PL : control Ilpum-leaf, PR : control Ilpum-root, LOL : OsSAP Ilmi transformantsleaf, LOR : OSSAP Ilmi transformants-root, POL : OSSAP Ilpum transformants-leaf, POR : OsSAP Ilpum transformants-root, LAL : AtBI-1 Ilmi transformants-leaf, LAR : AtBI-1 Ilmi transformants-root, PAL : AtBI-1 Ilpum transformants-leaf, PAR : AtBI-1 Ilpum transformants-root

the stress treatment (Fig. 6). Under salinity stress, $\mathrm{GA}_{3}$ accumulation was detected at minute levels under normal conditions, and was not detected in the leaves and roots of any of the transformants or controls after subjected to salinity stress. This indicates that $\mathrm{GA}_{3}$ probably does not play a role in the plants' response to salt stress conditions. The level of cytokinin and zeatin levels in transformants under salinity stress was also investigated. The level of zeatin in controls and transformants did not show a notable difference. Zeatin levels in controls dramatically decreased (i.e., one fold) in leaf and root tissue after one week of moderate stress, and prolonged salinity stress of two weeks. Comparisons of zeatin levels in control plants to transformant rice showed no difference after one and two weeks of salinity stress. However, auxin ICA levels in leaf tissue were slightly higher compared to the control plants following four days of drought treatment (Fig. 7).

\section{Discussion}

We investigated the in vivo function of OSSAP and AtBI-1. Rice cultivars, Ilmi and Ilpum, were transformed to overexpress the OsSAP and AtBI-1 gene under the control of a P35S promoter. Salt tolerance analysis of OSSAP and AtBI-1 transformants was performed by estimating the level of chlorophyll breakdown. After one and two weeks of salinity stress treatments, the chlorophyll units of all the transformants were significantly higher than the controls. It has been reported that a gene related to $B I-1$ is inducible under various abiotic and reactive oxygen stress conditions (Watanabe and Lam, 2008). The senescence associated protein encoded by OsSAP might be related to the Bax inhibitor gene because the plant BI-1 genes are also expressed in diverse tissue types and their expression levels are enhanced during aging and senescence (Kawai-Yamada et al. 2005b; Eichmann et al. 2004; and Bolduc et al. 2003). The present study also demonstrated $O S S A P$ to play a role in abiotic stress tolerance to drought and high salinity in rice. In addition, comparative analysis of AtBI-1 also showed similarity in tolerance inducement during salinity stress. The level of gene expression was also observed during salinity stress condition, where OSSAP and AtBI-1 transcripts were strongly detected in leaf and root tissues after one and two weeks of salinity stress in both Ilmi and Ilpum transformants. These observations on the transcript level provides evidence regarding the regulation of these genes for inducing tolerance towards the given stresses. In this study, the alteration of hormone levels in transformants overexpressing the anti-apoptosis genes $A t B I-1$ and $O S S A P$ was also reported. Transformants harboring AtBI-1 and OSSAP were used in the analysis. The alteration of hormone levels in rice represents distinct plant responses towards abiotic stress due to different defence mechanisms. Phytohormones are in a prominent position, playing important regulatory roles in plant physiology that affect developmental processes during abiotic stresses (Cheng et al. 2002; Browse, 2009). Three hormones (ABA, JA, Zeatin and $\mathrm{GA}_{3}$ ) with related defence mechanisms for abiotic stress, especially drought and salinity stress, were investigated. The role of ABA, JA, and SA as primary signals in the regulation of plant defence has been well established (Bari and Jones 2009; Pieterse et al. 2009). These hormones generate a signal transduction network that leads to a cascade of events responsible for the physiological adaptation of plants to stress. It was evident that ABA levels under drought stress increased in all leaf and root tissues for both $O S S A P$ and $A t B I-1$ transformants. The ABA level in the control rice also showed high accumulation in leaf tissue, but not in root tissue. Under salinity stress, the ABA level was not immediately affected, but slightly increased during prolonged stress after one week in the leaf tissue of 
OsSAP and AtBI-1 transformants. The ABA hormone is known for its regulatory role in integrating environmental adversity with the development of the plant (Christmann et al. 2005). ABA positively contributes toward adaptation to osmotic stress, a major component of several abiotic stressors (Kissoudis et al. 2014). ABA is a vital cellular signal that modulates the expression of a number of salt and water deficit-responsive genes (Fukuda and Tanaka 2006). Synthesis, degradation, and transport processes dynamically maintain ABA levels in plant cells. Therefore, plants maintain their developmental programs and stress responses by modulating endogenous ABA levels (Schwartz et al. 2003). However, it has been reported that $\mathrm{ABA}$ can stimulate production of anti-apoptotic proteins and reduces the expression in a number of pro-apoptotic proteins (Scarfi et al. 2009). This implies that the relation of ABA with OSSAP and AtBI-1 overexpression to anti-apoptosis could have connected pathways. There was no difference in JA levels under salinity stress between the transformants and the control, even after prolonged treatments. Jasmonic acid is a well-known signalling molecule in plant defence and stress responses (Hoeberrichts and Woltering 2003). The participation of JA in response to abiotic stress, such as drought and salinity, has been reported for several species. Stimulated water stress increased endogenous content of JA, followed by synthesis of jasmonate-induced proteins (Lehmann et al. 1995). It has been reported that tomato cultivars differ in salt tolerance due to different basal JA content. Steady-state amounts of JA and related compounds were higher for those that had salt tolerance (Pedranzani et al. 2003). In addition, it has been suggested that JA-related responses are directly associated with a reset, downstream of gene expression in the biosynthesis pathway (Thines et al. 2007). Together, these studies indicate that JA is an important component of a pathway that negatively regulates cell death and lesion formation. However, the precise mechanisms by which JA signalling regulates anti-apoptosis remain to be elucidated. The response of altered JA levels in the OSSAP and AtBI-1 transformants during critical conditions from salinity stress initially hypnotized the involvement of OSSAP in the JA physiological pathway. Plants have developed complex mechanisms to perceive external signals under salinity stress, allowing them to optimally respond to the environment. The plant hormones ABA, SA, JA, and ethylene regulate protective plant responses against abiotic and biotic stressors via synergistic and antagonistic actions that are referred to as signalling crosstalk (Fujita et al. 2006). JA and ABA might be connected in different stages of the response, driving an acclimation process during growth through an extensive genetic reprogramming to finally reach a new homeostasis (Harb et al. 2010). Overexpression of OsSAP and $A t B I-1$ can improve the endogenous levels of $\mathrm{ABA}$ and JA during salinity. We suggest that these anti-apoptosis genes involved in increasing the endogenous ABA and JA levels can sufficiently stimulate the preparatory response needed for drought acclimation. Investigation of $\mathrm{GA}_{3}$ levels under drought stress in transformed rice overexpressing OSSAP and $A t B I-1$ showed high accumulation levels of this hormone and was not detected in the controls. However, under salinity stress, $\mathrm{GA}_{3}$ was not detected in any of the transformants or controls. This is likely due to the low level of hormones extracted from rice plant tissue. These findings suggest that the hormones examined in this study are not related to abiotic stress response in rice. Cytokinin and zeatin affected leaves and roots differently. Drought stress dramatically decreased ICA levels, but no differences occurred between control and transformant plants. However, previous studies have shown that auxin is involved in the attenuation of defense responses in plants. While many components of the pathways act in a similar manner, and many genes are induced by abiotic stresses, it should be noted that the expression pattern of any specific gene varies in its timing and level of expression within specific tissues and under different experimental conditions. While the variation may occur because the treatments vary in their severity and duration, the hormonal status of the plants under different stress conditions may also affect cross-talk and the complex feedback regulatory mechanisms associated with the interacting pathways. However, the complex regulatory network of phytohormone signaling in plants subjected to abiotic stress needs to be explored, and the stress-related genes involved in the network of hormone signaling await identification. The changes in the levels of endogenous hormones in rice transformants overexpressing anti-apoptosis genes subjected to drought stress would allow a better understanding of the drought response and help in formulating improved strategies for generating drought tolerant crops.

\section{Acknowledgments}

This work was supported by a grant from the Next-Generation BioGreen21 Program(No. PJ011257012015), Rural Development Administration, Republic of Korea. This research was supported by Kyungpook National University Research Fund, 2015.

\section{References}

Aloni R, Aloni E, Langhans M, Ullrich CI (2006) Role of cytokinin 
and auxin in shaping root architecture:regulating vascular differentiation, lateral root initiation, root apical dominance and root gravitropism. Ann Bot 97:883-893

Bari R, Jones JDG (2009) Role of hormones in plant defense responses. Plant Mol Biol 69:473-488

Bolduc N, Ouellet M, Pitre F, Brisson LF (2003) Molecular characterization of two plant BI-1 homologues which suppress Bax-induced apoptosis in human 293 cells. Planta 216:377-386

Browse J. 2009. Jasmonate passes muster:a receptor and targets for the defense hormone. Annu. Rev. Plant Biol 60:183-205

Cheng WH, Endo A, Zhou L, Penney J, Chen HC, Arroyo A, Leon P, Nambara E, Asami T, Seo M, Koshiba T, Sheen J (2002) A unique short-chain dehydrogenase/reductase in Arabidopsis glucose signaling and abscisic acid biosynthesis and functions. Plant Cell 14:2723-2743

Christmann A, Hoffmann T, Teplova I, Grill E, Müller A (2005) Generation of active pools of abscisic acid revealed by in vivo imaging of water-stressed Arabidopsis. Plant Physiol 137:209-219

Eichmann R, Schultheiss H, Kogel KH, Hückelhoven R (2004) The barley apoptosis Suppressor homologue Bax inhibitor-1 compromises non host penetration resistance of barley to the in appropriate pathogen Blumeriagraminisf Sp. Tritici. Mol. Plant-Microbe Interact 17:484-490

Flowers TJ (2004) Improving crop salt tolerance. J Exp Bot 55:307-319

Fujita M, Fujita Y, Noutoshi Y, Takahashi F, Narusaka Y, Yamaguchi-Shinozaki K, Shinozaki K (2006) Crosstalk between abiotic and biotic stress responses:A current view from the points of convergence in the stress signaling networks. Curr Opin Plant Biol 9:436-442

Fukuda A, Tanaka Y (2006) Effects of ABA, auxin, and gibberellin on the expression of genes for vacuolar $\mathrm{H}^{+}$- inorganic pyrophosphatase, $\mathrm{H}^{+}$-ATPase subunit $\mathrm{A}$, and $\mathrm{Na}^{+} / \mathrm{H}^{+}$antiporter in barley. Plant Physiol Bioch 44:351-358

Golldack D, Li C, Mohan H, Probst N (2013) Gibberellins and abscisic acid signal crosstalk:living and developing under unfavorable conditions. Plant Cell Repots 32:1007-1016

Hanada M, Aimé-Sempé C, Sato T, Reed JC (1995) Structure function analysis of $\mathrm{Bcl}-2$ protein. Identification of conserved domains important for homodimerization with Bcl-2 and heterodimerization with Bax. J. Biol. Chem. 270:11962-11969

Harb A, Krishnan A, Ambavaram MM, Pereira A (2010) Molecular and physiological analysis of drought stress in Arabidopsis reveals early responses leading to acclimation in plant growth. Plant Physiol 154:1254-1271

Harrison MA (2012) Cross-talk between pytohormone signaling pathways under both optimal and stressful environmental condition. In:Phytohormone and abiotic stress tolerance in plants. Springers., Berlin/Heidelberg/New York., pp 49-76

Hoeberichts FA, Woltering EJ (2003) Multiple mediators of plant programmed cell death:interplay of conserved cell death mechanisms and plant-specific regulators. Bioessays 25:47-57

Hückelhoven R (2004) Bax inhibitor-1, an ancient cell death suppressor in animals and plants with prokaryotic relatives. Apoptosis 9:299-307
Isbat M, Zeba N, Kim SR, Hong CB (2009) A Bax inhibitor-1 gene in Capsicum annuum is induced under various abiotic stresses and endows multi-tolerance in transformants tobacco. J. Plant Physiol. 166:1685-1693

Kawai-Yamada M, Jin L, Yoshinaga K, Hirata A, Uchimiya H (2001) Mammalian Bax-induced plant cell death can be down Regulated by over-expression of Arabidopsis Bax Inhibitor-1 (AtBI-1). Proc. Natl. Acad. Sci. U.S.A. 98:12295-12300

Kawai-Yamada M, Yoshinaga K, Ogawa K, Ihara-Ohori Y, Uchimiya H (2005a) Oxidative stress and plant cell death suppressors. Plant Biotechnol 22:419-422

Kawai-Yamada M, Ohori Y, Uchimiya H (2004) Dissection of Arabidopsis BAX inhibitor-1 suppressing BAX-., hydrogen peroxide-., and salicylic acid-induced cell death. Plant Cell 16:21-32

Kawai-Yamada M, Saito Y, Jin L, Ogawa T, Kim KM, Yu LH, Tone Y, Hirata A, Umeda M, Uchimiya H (2005b) A novel Arabidopsis gene causes Bax-like lethality in Saccharomyces cerevisiae. J Biol Chem 280:39468-39473

Kissoudis C, van de Wiel C, Visser RG, van der Linden G (2014) Enhancing crop resilience to combined abiotic and biotic stress through the dissection of physiological and molecular crosstalk. Front Plant Sci 5:207

Kroemer G (1997) Theproto-oncogene Bcl-2 and it srolein regulating apoptosis. Nat Med 3:614-620

Lacomme C, Santa Cruz S (1999) Bax-induced cell death in tobacco is similar to hypersensitive response. Proc Natl Acad Sci USA 96:7956- 7961

Lehmann J, Atzorn R, Brückner C, Reinbothe S, Leopold J, Wasternack C, Parthier B (1995) Accumulation of Jasmonate, abscisic acid, specific transcripts and proteins in osmotically stressed barley leaf segments. Planta 197:156-162

Munns R (2002) Comparative physiology of salt and water stress. Plant, Cell and Environment 25:239-250

Munns R (2005) Genes and salt tolerance:bringing them together. New phytol 167:645-663

Pan X, Ruth W, Xuemin W (2010) Quantitative analysis of major plant hormones incrude plant extracts by high-performance liquid chromatography-mass spectrometry. Nat Protoc 56:986-992

Pedranzani H, Racagni G, Alemano S, Miersch O, Ramírez I, Peña Cortés H., Machado-Domenech E, Abdala G (2003) Salt tolerant tomato plants show increased levels of jasmonic acid. Plant Growth Regul 41:149-158

Pieterse CMJ, Leon-Reyes A, Van der Ent S, Van Wees SCM (2009) Networking by small-molecule hormones in plant immunity. Nat Chem Biol 5:308-316

Sanchez P, de Torres Zabala M, Grant M (2000) AtBI-1, a plant homologue of Bax inhibitor-1, suppresses BAX-induced cell death in yeast and is rapidly upregulated during wounding and pathogen challenge. Plant J 21:393-399

Sato T, Hanada M, Bodrug S, Irie S, Iwama N, Boise LH, Thompson CB, Golemis E, Fong L, Wang HG, Reed J (1994) Interactions among members of the bcl-2 protein family analyzed with a yeast-hybrid system. Proc Natl Acad Sci USA 91:9238-9242 
Scarfi S, Fresia C, Ferraris C, Bruzzone S, Fruscione F, Usai C, Benvenuto F, Magnone M, Podestà M, Sturla L, Guida L, Albanesi E, Damonte G, Salis A, De Flora A, Zocchi E (2009) The plant hormone abscisic acid stimulates the proliferation of human hemopoietic progenitors through the second messenger cyclic ADP-ribose. Stem Cells 10:2469-77

Schwartz SH, Qin X, Zeevaart JA (2003) Elucidation of the indirect pathway of abscisic acid biosynthesis by mutants, genes, and enzymes. Plant Physiol 131:1591-1601

Thines B, Katsir L, Melotto M, Niu Y, Mandaokar A, Liu G, Nomura K, He SY, Howe GA, Browse J (2007) JAZ repressor proteins are targets of the SCF (COI1) complex during jasmonate signalling. Nature 448:661-665

Ubaidillah M, Kim KA, Kim YH, Lee IJ, Yun BW, Kim DH, Loake GJ, Kim KM (2013) Identification of a drought-induced rice gene, OsSAP, that suppresses Bax-induced cell death in yeast. Mol Biol Rep 40:6113-6121

Watanabe N, Lam E (2008) BAX inhibitor-1 modulates endoplasmic reticulum stress-mediated programmed cell death in Arabidopsis. J Biol Chem 283:3200-3210

Yeo AR (2007). Salinity. In:Yeo AR, Flowers TJ, eds. Plant solute transport. Oxford:Blackwell Publishing Ltd, 340-365

Zhang J, Jia W, Yang J, Ismail AM (2006) Role of ABA in integrating plant responses to drought and salt stresses. Field Crop. Res. 97:111-119 